\title{
Recent progress in layered rare-earth hydroxide (LRH) and its application in luminescence
}

\author{
Qi ZHU ${ }^{a, b}$, Xuejiao WANG ${ }^{c, d}$, Ji-Guang $\mathrm{LI}^{a, b, c, *}$ \\ ${ }^{a}$ Key Laboratory for Anisotropy and Texture of Materials (Ministry of Education), Northeastern University, \\ Shenyang 110819, China \\ ${ }^{b}$ Institute of Ceramics and Powder Metallurgy, School of Materials Science and Engineering, \\ Northeastern University, Shenyang 110819, China \\ ${ }^{c}$ Research Center for Functional Materials, National Institute for Materials Science, \\ Namiki 1-1, Tsukuba, Ibaraki 305-0044, Japan \\ ${ }^{d}$ College of New Energy, Bohai University, Jinzhou 121000, China
}

Received: June 20, 2017; Revised: July 05, 2017; Accepted: July 12, 2017

(C) The Author(s) 2017. This article is published with open access at Springerlink.com

\begin{abstract}
This review article compiles the recent achievements made in layered rare-earth (RE) hydroxide (LRH), including controlled crystallization, structural and morphological features, anion exchange, nanosheet exfoliation, and application in the field of luminescence for both the $\mathrm{Ln}_{2}(\mathrm{OH})_{5}\left(\mathrm{~A}^{x-}\right)_{1 / x} \cdot n \mathrm{H}_{2} \mathrm{O}(251-\mathrm{LRH})$ and $\mathrm{Ln}_{2}(\mathrm{OH})_{4}\left(\mathrm{~A}^{x-}\right)_{2 / x} \cdot n \mathrm{H}_{2} \mathrm{O}$ (241-LRH) phases. The luminescent properties of the LRHs themselves, the oxide, oxysulfate, and oxysulfide phosphors derived from the LRHs via controlled calcination, and the highly oriented transparent phosphor films of enhanced luminescence and/or novel emission features are summarized.
\end{abstract}

Keywords: layered rare-earth hydroxide (LRH); anion exchange; exfoliation; assembly; luminescence

\section{Introduction}

Layered inorganic compounds, including the anion-type, cation-type, and neutral-type (such as graphite), have been drawing keen research interest during the very recent years. Owing to their unique combination of a layered crystal structure and rich interlayer chemistry (anion exchange and intercalation), the compounds are finding a wide range of applications in rechargeable batteries, pollutant trapping, heterogeneous catalysis, drug delivery, microelectronics, and so forth [1]. Another unique and fascinating feature of the layered compounds is that they may potentially be exfoliated into unilamellar nanosheets or nanosheets of few-layer thickness [2]. The anion-type layered compounds are

* Corresponding author.

E-mail: LI.Jiguang@nims.go.jp three-dimensional crystals built up via repetitive stacking of two-dimensional infinite nanosheets with positive charges that are neutralized by the anions accommodated in the interlayer gallery, and is vice versa for the cation type [3]. The atoms in the main host are held together primarily by covalent bonding so as to form substantially rigid two-dimensional layers, while the interaction between the charged layers can be much weaker [3]. One typical and widely studied example of the anion type is the layered double hydroxides (LDHs, $\left[M_{1-x}^{2+} M_{x}^{3+}(\mathrm{OH})_{2}\right]^{x+}\left[A_{x / m}^{m-}\right]^{x-} \cdot n \mathrm{H}_{2} \mathrm{O}$, where $M$ represents a metal cation and $A$ denotes interlayer anion [4]). The composition is diverse as the general formula suggests, but all the components are isostructural and are derived from brucite $\left[\mathrm{Mg}(\mathrm{OH})_{2}\right]$, which consists of $\mathrm{Mg}(\mathrm{OH})_{6}$ octahedra sharing edges to form infinite charge-neutral layers. Partial substitution of the $M^{2+}$ ions by $M^{3+}$ renders layers that acquire a positive charge, which is 
balanced by an interlayer counter anion between the two brucite-like slabs [4]. Layered rare-earth hydroxides (LRHs), having the general formula of $\mathrm{Ln}_{2}(\mathrm{OH})_{6-m}\left(\mathrm{~A}^{x-}\right)_{m / x} \cdot n \mathrm{H}_{2} \mathrm{O}$ (Ln: trivalent rare-earth ions; A: intercalated anion; $1.0 \leqslant m \leqslant 2.0$ ), are a new family of anion-type inorganic layered compounds, but exclusively contain $\mathrm{Ln}^{3+}$ cations in the host layers [5-7]. Due to the unique electronic, optical, magnetic, and catalytic properties of the Ln elements, the LRHs are attracting continuous attention since their emergence in 2006 [5], and extensive efforts have been paid to their synthesis, structural characterization, anion exchange, and exfoliation. $\mathrm{Ln}_{2}(\mathrm{OH})_{5}\left(\mathrm{~A}^{x-}\right)_{1 / x} \cdot n \mathrm{H}_{2} \mathrm{O}(m=1, n=1-2$, and typically $n \approx 1.5$; termed as the 251-LRH phase) [5-7] and $\mathrm{Ln}_{2}(\mathrm{OH})_{4}\left(\mathrm{~A}^{x-}\right)_{2 / x} \cdot n \mathrm{H}_{2} \mathrm{O} \quad(m=2, \quad n=0-2$; 241-LRH phase) [8,9] are two important groups of the LRHs family. The anions (such as $\mathrm{NO}_{3}^{-}, \mathrm{Cl}^{-}$, and $\mathrm{Br}$ ) in the 251-LRH phase of $n \approx 1.5$ frequently exist in the interlayer gallery as free ones (not coordinated to the $\mathrm{Ln}^{3+}$ center) and thus exhibit facile exchange with a wide range of carboxylate and sulfonate anions [10-15]. Therefore, the 251-LRHs may potentially be exfoliated into single-layer nanosheets of significantly two-dimensional morphologies for the further construction of various nanostructures, particularly highly transparent functional films. The 241-LRH phase, on the other hand, is rigidly pillared by the interlayer anions (typical of $\mathrm{SO}_{4}^{2-}$ ) $[8,9]$, and thus exfoliation of its bulk crystals into nanosheets with the strategy applied for 251-LRHs has not been achieved. The LRHs of the 251 and 241 phases, both having Ln centers in the hydroxide host layers, represent a new class of luminescent materials. In addition, some important categories of phosphors, including oxide, oxysulfate, and oxysulfide, can be facilely converted from the LRHs via proper annealing. This review article summarizes the recent achievements attained in the fascinating field of LRHs, including controlled crystallization, structural and morphological features, anion exchange and exfoliation, and application in phosphors and transparent films.

\section{Controlled crystallization and structural and morphological features}

\section{2. $1 \operatorname{Ln}_{2}(\mathrm{OH})_{5}\left(\mathrm{~A}^{\mathrm{X}-}\right)_{1 / x^{\prime}} \cdot n \mathrm{H}_{2} \mathrm{O}(251-\mathrm{LRH})$}

Homogeneous precipitation, hydrothermal reaction, and titration are the main techniques to obtain 251-LRHs. Two types of Ln environments exist in the crystal structure of 251-LRH, that is, 8-fold coordinated $\left[\mathrm{Ln}(\mathrm{OH})_{7} \mathrm{H}_{2} \mathrm{O}\right]$ and 9-fold coordinated $\left[\mathrm{Ln}(\mathrm{OH})_{8} \mathrm{H}_{2} \mathrm{O}\right]$ polyhedrons (Fig. 1). Each $\mathrm{LnO}_{8}$ polyhedron is linked to two other $\mathrm{LnO}_{8}$ polyhedra and four $\mathrm{LnO}_{9}$ polyhedra via edge sharing, and the linked polyhedron units then form a two-dimensional host layer parallel to the $a b$ plane (Fig. 1) [5]. The $\mathrm{A}^{x-}$, typically of $\mathrm{NO}_{3}^{-} / \mathrm{Cl}^{-} / \mathrm{Br}^{-}$ $(x=1)$ and $\mathrm{SO}_{4}^{2-}(x=2)$, is mainly located in the interlayer space to support the layers, and the loss of coordinated water molecules will result in an abrupt layer contraction [10-15]. The hydration number tends to decrease with increasing atomic number for the chloride family (orthorhombic structure) while increase for the nitrate analogue (monoclinic structure) $[6,11]$. The synthesis of 251-LRHs for the full spectrum of lanthanides (including Y) was pursued by several research groups including us. A series of 251-LRHs, with single-phase products for $\mathrm{Sm}-\mathrm{Er}$ and $\mathrm{Y}$, have been synthesized by homogeneous precipitation, which involves refluxing an aqueous solution containing the corresponding Ln salt (nitrate or chloride) and hexamethylenetetramine precipitant [6]. Solvothermal reaction, however, is needed to extend the nitrate family of 251-LRHs to the bigger ions of $\mathrm{Gd}, \mathrm{Eu}, \mathrm{Nd}$,

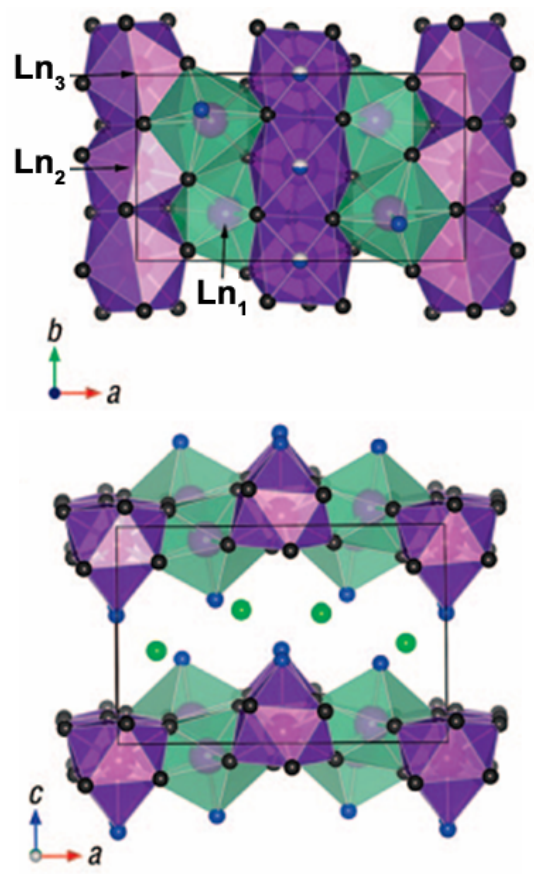

Fig. 1 A schematic illustration of the crystal structure of $\mathrm{Ln}_{2}(\mathrm{OH})_{5} \mathrm{Cl} \cdot n \mathrm{H}_{2} \mathrm{O}$. Reproduced with permission from Ref. [6], (C) American Chemical Society 2008. 
and $\mathrm{La}[16,17]$. The work by McIntyre et al. [14] found that the small $\mathrm{Yb}^{3+}$ ion tends to precipitate as a phase mixture of $\mathrm{Yb}_{2}(\mathrm{OH})_{5} \mathrm{NO}_{3} \cdot \mathrm{H}_{2} \mathrm{O}, \mathrm{Yb}_{2}(\mathrm{OH})_{5} \mathrm{NO}_{3} \cdot 1.5 \mathrm{H}_{2} \mathrm{O}$, and $\mathrm{Yb}_{2}(\mathrm{OH})_{5} \mathrm{NO}_{3} \cdot 2 \mathrm{H}_{2} \mathrm{O}$, and the anion exchangeable $\mathrm{Yb}_{2}(\mathrm{OH})_{5} \mathrm{NO}_{3} \cdot 1.5 \mathrm{H}_{2} \mathrm{O}$ compound can only be obtained as a single phase via controlling crystallization kinetics. The successful synthesis of 251-LRH for the smallest $\mathrm{Lu}^{3+}$ has not been achieved up to date to the best of our knowledge. Hydrothermal reaction in the presence of alkali-metal hydroxide or ammonium hydroxide is currently the most widely used technique for LRH synthesis, and phase composition of the hydrothermal product is found to be rather sensitive to the processing conditions. For the $\mathrm{Y} / \mathrm{Eu}$ binary system, reacting at $120{ }^{\circ} \mathrm{C}$ and $\mathrm{pH} \approx 7$ would yield 251 -LRH solid-solution crystallites of a uniform hexagonal crystal shape, with the lateral sizes of $\sim 1 \mu \mathrm{m}$ and thicknesses of $\sim 90 \mathrm{~nm}$ (Fig. 2(c)) [7]. Higher $\mathrm{pH}$ values and higher temperatures would, however, lead to $\mathrm{Ln}_{4} \mathrm{O}(\mathrm{OH})_{9} \mathrm{NO}_{3}, \mathrm{Ln}(\mathrm{OH})_{2.94}\left(\mathrm{NO}_{3}\right)_{0.06} \cdot n \mathrm{H}_{2} \mathrm{O}$, and even $\mathrm{Ln}(\mathrm{OH})_{3}$ crystallization [18]. Ammonium nitrate $\left(\mathrm{NH}_{4} \mathrm{NO}_{3}\right)$ was found to be an effective mineralizer to significantly widen the formation domain of the nitrate-type 251 -LRHs (up to $200{ }^{\circ} \mathrm{C}$ under $\mathrm{pH} \approx 7-8$ ), so that much larger crystals, with the lateral size up to $0.3 \mathrm{~mm}$ (Figs. 2(a) and 2(b)), can be obtained via hydrothermal reaction [18]. The reason is that the $\mathrm{Ln}^{3+}$ ion presents as $\left[\mathrm{Ln}(\mathrm{OH})_{x}\left(\mathrm{NO}_{3}\right)_{y}\left(\mathrm{H}_{2} \mathrm{O}\right)\right]^{3-x-y}$ complex in an aqueous solution, and the $\mathrm{OH}^{-}$and $\mathrm{NO}_{3}^{-}$anions compete with each other to coordinate $\mathrm{Ln}^{3+}$. Increasing temperature or solution $\mathrm{pH}$ would yield more $\mathrm{OH}^{-}$ while less $\mathrm{NO}_{3}^{-}$in the complex and thus lead to products of successively lower $\mathrm{NO}_{3}^{-} / \mathrm{OH}^{-}$molar ratio [18]. The $\mathrm{NH}_{4} \mathrm{NO}_{3}$ mineralizer provides additional $\mathrm{NO}_{3}^{-}$to balance off the effects of temperature or $\mathrm{pH}$ increase,
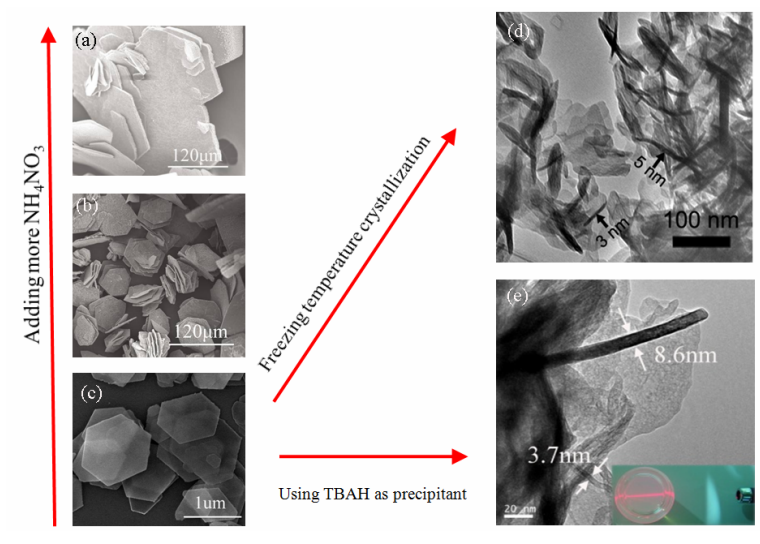

Fig. 2 Representative morphologies of the $(\mathrm{Y}, \mathrm{Eu})_{2}(\mathrm{OH})_{5} \mathrm{NO}_{3} \cdot n \mathrm{H}_{2} \mathrm{O}$ crystals obtained under different conditions. and thus the formation domain of nitrate-type 251-LRHs can be substantially widened. On the other hand, 251-LRH nanoplates of a few layers thick can be obtained by effectively suppressing the high-activationenergy thickness growth along the $c$-axis through surface capping or low-temperature precipitation. In the former case, tetrabutylammonium hydroxide (TBAOH, $\left.\left(\mathrm{C}_{4} \mathrm{H}_{9}\right)_{4} \mathrm{~N}^{+} \cdot \mathrm{OH}^{-}\right)$was found to be effective, since it not only supplies precipitating $\mathrm{OH}^{-}$but also stabilizes the building units (host layers) of LRH via surface adsorption of the $\left(\mathrm{C}_{4} \mathrm{H}_{9}\right)_{4} \mathrm{~N}^{+}\left(\mathrm{TBA}^{+}\right)$ions left behind (Fig. 2(e)) [19]. In the latter case, the freezing temperature of $\sim 4{ }^{\circ} \mathrm{C}$ was shown to be low enough to effectively suppress the thickness growth along the $c$-axis while high enough to crystallize the hydroxide main layers (the $a b$ planes) [20]. With the latter technique, single-phase nitrate-type 251-LRH nanosheets of only $\sim 4 \mathrm{~nm}$ in thickness have been synthesized in large quantities for a wide spectrum of Ln ( $\mathrm{Ln}=\mathrm{Pr}, \mathrm{Nd}, \mathrm{Sm}, \mathrm{Eu}, \mathrm{Gd}, \mathrm{Tb}, \mathrm{Dy}, \mathrm{Y}, \mathrm{Ho}$, and Er) (Fig. 2(d)) [20]. It was also shown that the solution $\mathrm{pH}$ needed for LRH crystallization successively decreases with decreasing ionic radius of $\mathrm{Ln}^{3+}$ owing to the gradually higher extent of $\mathrm{Ln}^{3+}$ hydrolysis following lanthanide contraction [20]. For the Y-based 251-LRHs, it was shown that Eu incorporation led to steadily smaller crystallites, elongation of the well-developed hexagon platelets, and linearly expanded $a b$ plane of the layered structure, while the interlayer distance $(c / 2)$, closely related to the hydration number $n$, is inversely proportional to the Eu content (Fig. 3) [7]. A lower hydration by $\mathrm{Eu}^{3+}$ doping was found to shift the $\mathrm{Eu}^{3+}$ coordination from $C_{4 v}$ to $C_{1}$ symmetries [7]. Similar phenomena were observed for the incorporation of other lager $\mathrm{Ln}^{3+}$, such as $\mathrm{Gd}^{3+}$ or $\mathrm{Tb}^{3+}$ [21-23]. It should be noted that, up to date, the sulfate-type 251-LRH of $\mathrm{Ln}_{2}(\mathrm{OH})_{5}\left(\mathrm{SO}_{4}\right)_{0.5} \cdot n \mathrm{H}_{2} \mathrm{O}$ was exclusively obtained via $\mathrm{SO}_{4}^{2-}$ exchange of the $\mathrm{NO}_{3}^{-}$or $\mathrm{Cl}^{-}$in the interlayer of the 251-LRHs crystallized beforehand. Our recent work showed that $\left(\mathrm{Gd}_{1-x} \mathrm{~Tb}_{x}\right)_{2}(\mathrm{OH})_{5}\left(\mathrm{SO}_{4}\right)_{0.5} \cdot n \mathrm{H}_{2} \mathrm{O}$ nanoplates $(x=0.06-0.10)$, with the lateral sizes of $\sim 450-1000 \mathrm{~nm}$ and thicknesses of $\sim 65-85 \mathrm{~nm}$, can be directly synthesized via hydrothermal reaction in the presence of $\left(\mathrm{NH}_{4}\right)_{2} \mathrm{SO}_{4}$ under the mild conditions of $\sim 120{ }^{\circ} \mathrm{C}$ and $\mathrm{pH} \approx 10$ [15].

\section{$2.2 \mathrm{Ln}_{2}(\mathrm{OH})_{4} \mathrm{SO}_{4} \cdot n \mathrm{H}_{2} \mathrm{O}(241-\mathrm{LRHs})$}

The 241-LRH compounds of $\mathrm{Ln}_{2}(\mathrm{OH})_{4} \mathrm{SO}_{4} \cdot 2 \mathrm{H}_{2} \mathrm{O}$ are crystallized in the monoclinic system (space group: 


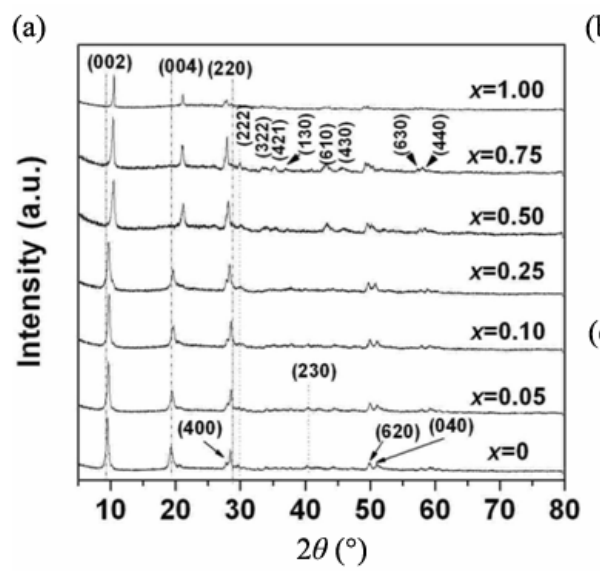

(b)

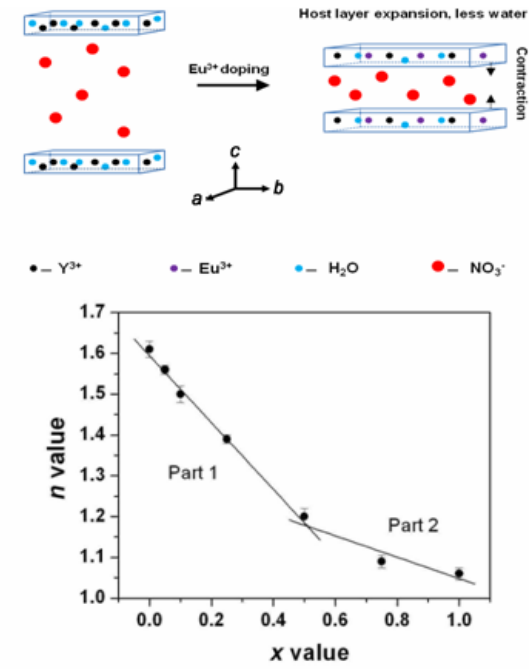

Fig. 3 (a) XRD patterns and (c) the hydration number $n$ of $\left(\mathrm{Y}_{1-x} \mathrm{Eu}_{x}\right)_{2}(\mathrm{OH})_{5} \mathrm{NO}_{3} \cdot n \mathrm{H}_{2} \mathrm{O}$ as a function of the Eu content ( $x$ value). (b) Structure changes induced by $\mathrm{Eu}^{3+}$ doping. Reproduced with permission from Ref. [7], (C) American Chemical Society 2010.

$C 2 / m$ ), and the structure is built up via alternative stacking of the interlayer sulfate ions and the $\left[\mathrm{LnO}_{9}\right]$ polyhedra containing two-dimensional host layers along the $a$-axis (Fig. 4) [9]. The sulfate group bonds to two Ln cations separately residing in the adjacent layers and links the layers via trans-bidentate coordination (Fig. 4) [9]. Homogeneous precipitation and hydrothermal reaction are the two main ways to obtain 241-LRHs. The former technique seems limited to intermediately sized $\mathrm{Ln}^{3+}$, and a series of single-phase 241-LRHs $(\mathrm{Ln}=\mathrm{Pr}-\mathrm{Tb})$ have been synthesized through homogeneous hydrolysis of $\mathrm{Ln}$ sulfates in the presence of hexamethylenetetramine [8]. We recently proposed hydrothermal reaction for the controlled crystallization of 241-LRHs, using Ln nitrate and $\left(\mathrm{NH}_{4}\right)_{2} \mathrm{SO}_{4}$ as the reactants, and successfully extended this family of compounds to the larger $\mathrm{Ln}^{3+}$ of $\mathrm{La}$ and smaller $\mathrm{Ln}^{3+}$ of Dy [24]. Reaction temperature and solution $\mathrm{pH}$ were identified as two most influential factors that determine the phase constituent of the hydrothermal product [24], which can also be understood in view of lanthanide contraction. For example, under the same hydrothermal conditions of $100{ }^{\circ} \mathrm{C}$ and $\mathrm{pH}=9$, the larger $\mathrm{Ln}^{3+}$ of La-Gd crystallized as 241-LRHs while the smaller ones of $\mathrm{Tb}^{3+}$ and $\mathrm{Dy}^{3+}$ were formed as the more $\mathrm{OH}^{-}$ containing 251-LRHs of $\mathrm{Ln}_{2}(\mathrm{OH})_{5}\left(\mathrm{SO}_{4}\right)_{0.5} \cdot n \mathrm{H}_{2} \mathrm{O}$ owing to their higher extent of hydrolysis [24]. This rationalization was supported by the fact the 241-LRHs of $\mathrm{Tb}$ and $\mathrm{Dy}$ can be produced at $100{ }^{\circ} \mathrm{C}$ under the lower $\mathrm{pH}$ of 7 , since a lower $\mathrm{pH}$ suppresses the hydrolysis of $\operatorname{Ln}^{3+}$ [24]. The lattice parameters $(a, b$, and $c)$, cell volume, and axis angle of the 241-LRHs across the lanthanide series $(\mathrm{Ln}=\mathrm{La}-\mathrm{Dy})$ monotonously decrease as the size of $\mathrm{Ln}^{3+}$ decreases [24]. The particle morphology was found to be significantly affected by the solution $\mathrm{pH}$. In a neutral or acidic solution, aggregates were formed since the protonated crystallite surfaces electrostatically attract negatively charged $\mathrm{SO}_{4}^{2-}$ anions and as a result the primary crystallites were glued together [24]. As seen from Fig. $4(\mathrm{pH}=7)$,
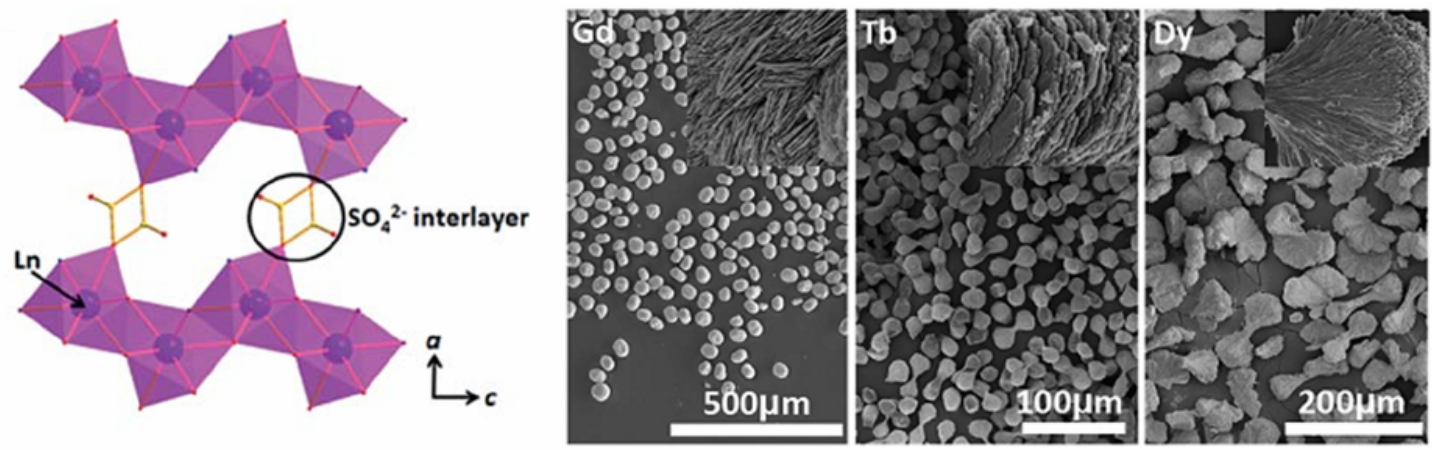

Fig. 4 Illustration of the stacking pattern of the crystal structure of $\mathrm{Dy}_{2}(\mathrm{OH})_{4} \mathrm{SO}_{4} \cdot n \mathrm{H}_{2} \mathrm{O}$ 241-LRH (left) and SEM images of the $\mathrm{Ln}_{2}(\mathrm{OH})_{4} \mathrm{SO}_{4} \cdot 2 \mathrm{H}_{2} \mathrm{O}$ 241-LRH products obtained via controlled hydrothermal reaction ( $\mathrm{Ln}=\mathrm{Gd}$, Tb, and Dy; right). Reproduced with permission from Ref. [24], (C) The Royal Society of Chemistry 2017. 
the well dispersed 241-LRH particles of Gd (spheres, $\sim 50 \mu \mathrm{m}), \mathrm{Tb}$ (peanuts-shaped, $\sim 40 \mu \mathrm{m}$ in length), and Dy (dumbbell-shaped, up to $\sim 130 \mu \mathrm{m}$ in length) are all aggregated from thin platelet microcrystallites [24]. Dispersed thin-plate-like crystallites of the 241-LRHs can be produced in an alkaline solution (such as $\mathrm{pH}=9$ ), since the crystallite surfaces are hardly protonated, as observed from the products of $\mathrm{Ln}=\mathrm{La}-\mathrm{Gd}[24]$.

\section{Anion exchange and nanosheets exfoliation}

The $\mathrm{A}^{x-}$ of 251-LRHs (such as $\mathrm{NO}_{3}^{-}, \mathrm{Cl}^{-}$, and $\mathrm{Br}^{-} ; x=1$ ) and 241-LRHs (such as $\mathrm{SO}_{4}^{2-} ; x=2$ ) is mainly in the interlayer supporting the layers. The A anions in the 251-LRHs are generally not coordinated to the $\mathrm{Ln}^{3+}$ centers and thus can undergo facile exchanges with a wide range of organic dicarboxylate anions, but the 241-LRHs are rigidly pillared by sulfate ions and are not anion-exchangeable. Therefore, the recent achievements summarized in this section are focused on 251-LRHs. The exchange can be simply achieved by immersing the pristine crystallites in an aqueous solution containing the sodium salt of the desired anion in an excessive dosage. Taking $\mathrm{Y}_{2}(\mathrm{OH})_{5} \mathrm{NO}_{3} \cdot n \mathrm{H}_{2} \mathrm{O}$ for example, the interlayer $\mathrm{NO}_{3}^{-}$was confirmed to be exchangeable at room temperature by either monovalent $\mathrm{F}^{-}$or divalent $\mathrm{SO}_{4}^{2-}$ [20], which is also applicable to the 251-LRHs of other Ln members. The basal spacings of the pristine and anion exchanged products can be rationalized by considering the geometric size/orientation of the anions in the interlayer and particularly the host-anion interaction via electrostatic attraction and hydrogen bonding [20]. It is known that layered materials may swell and delaminate into nanosheets in water or an organic solvent under certain conditions. Similar to the procedures applied for LDHs, the 251-LRH crystals can be exfoliated into single-layer nanosheets of $\sim 1.6 \mathrm{~nm}$ thick in formamide after exchanging the interlayer anions with dodecylsulfonate $\left(\mathrm{C}_{12} \mathrm{H}_{25} \mathrm{OSO}_{3}^{-}, \mathrm{DS}^{-}\right)$[25]. The resultant nanosheets are, however, frequently limited to $\sim 500 \mathrm{~nm}$ in lateral size due to the small size of the starting crystals (up to $\sim 5 \mu \mathrm{m}$ ) and cracking of the nanosheets under lengthy (several days) mechanical agitation for exfoliation [26]. The LRH crystals synthesized with $\mathrm{NH}_{4} \mathrm{NO}_{3}$ as a mineralizer, having a lateral size of $\sim 300 \mu \mathrm{m}$ and a thickness of $\sim 9 \mu \mathrm{m}$ (Fig. 2(a)) [18], are attractive starting crystals for the exfoliation of ultra-large nanosheets, but successful insertion of $\mathrm{DS}^{-}$anions into the interlayers is rather challenging at room temperature owing to the very large crystal size. We recently proposed hydrothermal exchange of the interlayer $\mathrm{NO}_{3}^{-}$for so large LRH crystals, and through kinetics study a "wriggle intercalation" model was proposed for the $\mathrm{DS}^{-}$anions (Fig. 5(a)) [25]. Compared with the traditional anion exchange at room temperature, hydrothermal processing not only shortened the exchange time from 720 to $24 \mathrm{~h}$ but also significantly enlarged the basal spacing [25]. Unilamellar nanosheets with the large lateral size of more than $60 \mu \mathrm{m}$ and a thickness of only $\sim 1.6 \mathrm{~nm}$ (single layer) have then been obtained by delaminating the $\mathrm{DS}^{-}$intercalated $\mathrm{LRH}$ in formamide (Figs. 5(b)-5(e)) [25]. The interlayer spacing of LRH is significantly affected by the size of the intercalated anions, and a more weakened interlayer interaction by inserting bigger anions is benificial to exfoliation. The water-soluble $\mathrm{DS}^{-}$, which has a long carbon chain, is usually employed to swell anion-type layered compounds via room temperature anion exchange, and successes were manifested in the cases of LDHs and LRHs. The anions of even longer carbon chains, such as oleate $\left(\mathrm{C}_{17} \mathrm{H}_{33} \mathrm{COO}^{-}\right)$, are expected to be more efficient for interlayer expansion but are hardly soluble in water at room temperature. We reported the successful insertion of oleate anions into the interlayers of tens of micron-sized 251-LRH crystals via hydrothermal anion exchange, based on which efficient exfoliation of ultra-large $(\sim 20 \mu \mathrm{m})$ and single layer $(\sim 1.55 \mathrm{~nm}$ thick) nanosheets in toluene was achieved [27].

\section{Application in phosphors and transparent films}

The 251- and 241-LRHs, with Ln centers in the host layers, represent a new class of luminescent materials. In addition, the important phosphor families of oxide, oxysulfate, and oxysulfide can all be facilely converted from LRHs via proper annealing. This section focuses on the applications of the LRHs and their nanosheets in phosphors and transparent films.

\section{4. $1 \operatorname{Ln}_{2}(\mathrm{OH})_{5}\left(\mathrm{~A}^{x-}\right)_{1 / x^{\prime}} \cdot \mathrm{nH}_{2} \mathrm{O}$ (251-LRHs)}

$\mathrm{Eu}^{3+}$ and $\mathrm{Tb}^{3+}$ typically exhibit line-like red and green 


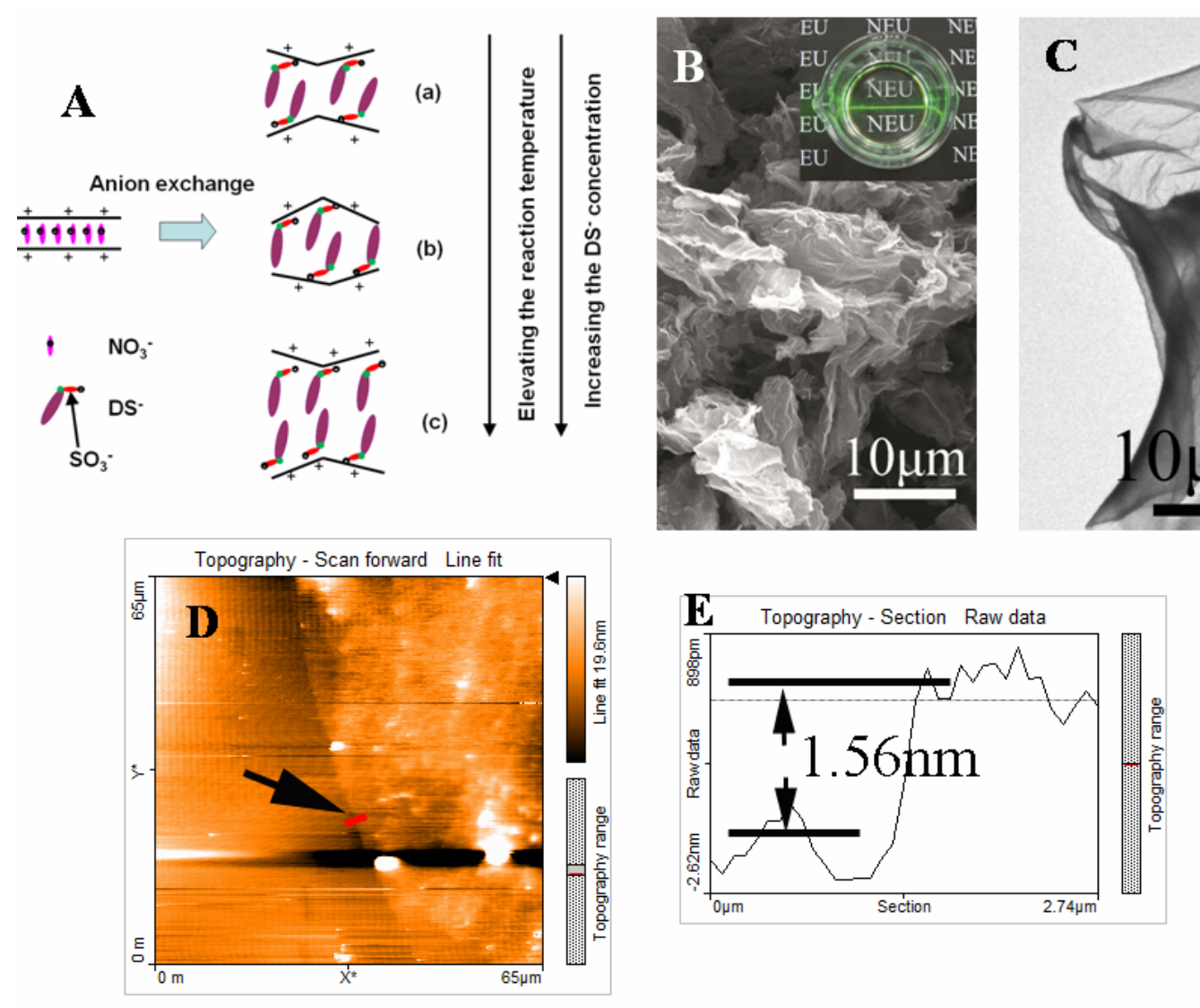

Fig. 5 (A) Schematic illustration of $\mathrm{DS}^{-}$arrangement in the interlayer, and (B) FE-SEM, (C) TEM, and (D) AFM micrographs showing morphologies of the nanosheets exfoliated from $(\mathrm{Y}, \mathrm{Eu})_{2}(\mathrm{OH})_{5} \mathrm{NO}_{3} \cdot n \mathrm{H}_{2} \mathrm{O}$ crystals $(0.3 \mathrm{~mm}$-sized). (E) Height profile along the red line marked in (D). The inset in (B) shows the appearance of a colloidal suspension of the nanosheets in formamide with a clearly observable Tyndall effect under laser beam irradiation. Reproduced with permission from Ref. [25], (C) National Institute for Materials Science 2014.

emissions, respectively, which find wide applications in the areas such as fluorescent lamps, white light emitting diodes (white LEDs), plasma display panels (PDPs), flat panel displays (FDPs), field emission displays (FEDs), and cathode ray tubes (CRTs). In $\left(\mathrm{Y}_{1-x} \mathrm{Eu}_{x}\right)_{2}(\mathrm{OH})_{5} \mathrm{NO}_{3} \cdot n \mathrm{H}_{2} \mathrm{O}$, decreasing hydration shifts the coordination environment of $\mathrm{Eu}^{3+}$ from $C_{4 v}$ to $C_{1}$ symmetries and thus leads to systematically varied photoliminescence behaviors (Fig. 6) [7]. The $C_{1}$-site $\mathrm{Eu}^{3+}$ ions were found to be significantly associated with the ${ }^{5} \mathrm{D}_{0} \rightarrow{ }^{7} \mathrm{~F}_{1}$ transition at $595 \mathrm{~nm}$ and the ${ }^{5} \mathrm{D}_{0} \rightarrow{ }^{7} \mathrm{~F}_{2}$ transition at $615 \mathrm{~nm}$, while the $C_{4 v}$-site $\mathrm{Eu}^{3+}$ is associated with the $589 \mathrm{~nm}{ }^{5} \mathrm{D}_{0} \rightarrow{ }^{7} \mathrm{~F}_{1}$ and $698 \mathrm{~nm}$ ${ }^{5} \mathrm{D}_{0} \rightarrow{ }^{7} \mathrm{~F}_{4}$ transitions (Fig. 6) [7]. The incorporated $\mathrm{Gd}^{3+}$ cations selectively sensitize the emission from the $C_{1}$-site $\mathrm{Eu}^{3+}$ and produce an additional charge transfer (CT) excitation band at $254 \mathrm{~nm}$ [28]. With this, the desired 615-nm red emission is obtainable either under intra- $4 \mathrm{f}^{6}$ excitation of $\mathrm{Eu}^{3+}$ or by exciting the $\mathrm{CT}$ band [28]. The LRHs convert to cubic solid-solutions of $\left(\mathrm{Y}_{1-x} \mathrm{Eu}_{x}\right)_{2} \mathrm{O}_{3}$ at temperatures $\geqslant 400{ }^{\circ} \mathrm{C}$ via a $\left(\mathrm{Y}_{1-x} \mathrm{Eu}_{x}\right)_{2} \mathrm{O}_{2}(\mathrm{OH}) \mathrm{NO}_{3}$ intermediate while retaining the original particle morphologies [7]. The oxide with $x=0.05$ exhibits the best luminescence for the 613-nm red emission under UV excitation at $255 \mathrm{~nm}$, and significant luminescence quenching was observed at $x>$ 0.10 [7]. On the other hand, the nanosheets exfoliated from 251-LRHs tend to orient themselves with a certain crystallographic direction perpendicular to the substrate surface, owing to their significantly two-dimensional morphologies, which may introduce additional or greatly enhanced functionalities. The projection in the [001] direction for the 251-LRH crystal and in the [111] direction for the derived cubic oxide $\left(\mathrm{Ln}_{2} \mathrm{O}_{3}\right)$ present close similarities in terms of the atomic configuration of $\mathrm{Ln}$, and thus the phase transformation from LRH to $\mathrm{Ln}_{2} \mathrm{O}_{3}$ occurs quasi-topotactically [19]. In view of these, a number of studies have been focused on the construction of oriented fluorescent films, and the transparent oxide phosphor films of the $\mathrm{Y} / \mathrm{Eu}[19,25]$, 


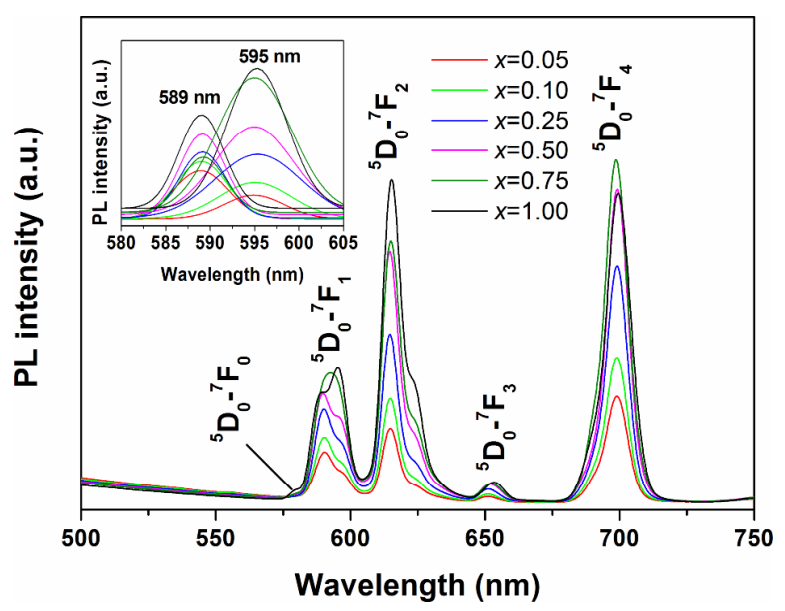

Fig. 6 Photoluminescence (PL) spectra of $\left(\mathrm{Y}_{1-x} \mathrm{Eu}_{x}\right)_{2}(\mathrm{OH})_{5} \mathrm{NO}_{3} \cdot n \mathrm{H}_{2} \mathrm{O}$. The PL spectra are measured under intra $4 \mathrm{f}^{6}$ electronic excitation of $\mathrm{Eu}^{3+}$ at $395 \mathrm{~nm}$. Inset is the two ${ }^{5} \mathrm{D}_{0} \rightarrow{ }^{7} \mathrm{~F}_{1}$ peaks deconvoluted by Gaussian fitting. Reproduced with permission from Ref. [7], (C) American Chemical Society 2010.

$\mathrm{Y} / \mathrm{Tb} / \mathrm{Eu}$ [27], $\mathrm{Y} / \mathrm{Gd} / \mathrm{Eu}$ [21], and $\mathrm{Y} / \mathrm{Gd} / \mathrm{Dy}$ [29] systems with a uniform [111] orientation, a layer thickness of $\sim 90 \mathrm{~nm}$, and a high transmittance of $\geqslant$ $80 \%$ have been constructed with the exfoliated and the as-formed nanosheets as building blocks via spin-coating and self-assembly, followed by proper annealing (Fig. 7). Owing to the significant [111] orientation, the oriented $\mathrm{Y} / \mathrm{Eu}$ oxide films were observed to exhibit emissions up to 4 times that of the powder form (Fig. 7). $\mathrm{Gd}^{3+}$ doping led to greatly enhanced emission owing to the sensitizing effects of $\mathrm{Gd}^{3+}$, while multi-color emissions ranging from red, orange, yellow, and then to green can be achieved by co-doping of $\mathrm{Eu}^{3+}$ and $\mathrm{Tb}^{3+}$ and via the efficient $\mathrm{Tb}^{3+} \rightarrow \mathrm{Eu}^{3+}$ energy transfer. Besides, inserting rare-earth ions and/or organic sensitizers into the interlayer gallery of LRHs may allow the appearance of strong "synergistic effect" [30-35], with which hybrid phosphors can be successfully fabricated to achieve enhanced and color tunable emissions [30-32]. White-light emitting hybrid phosphors and nano-composite films have also been successfully designed and fabricated, utilizing the energy transfer from $\mathrm{Tb}^{3+}$ to $\mathrm{Eu}^{3+}$ and from an organic sensitizer (such as PMMA) to the activator [31,32].

\section{4. $2 \mathrm{Ln}_{2}(\mathrm{OH})_{4} \mathrm{SO}_{4} \cdot 2 \mathrm{H}_{2} \mathrm{O}$ (241-LRHs)}

Rare-earth oxysulfate $\left(\mathrm{Ln}_{2} \mathrm{O}_{2} \mathrm{SO}_{4}\right)$ and oxysulfide $\left(\mathrm{Ln}_{2} \mathrm{O}_{2} \mathrm{~S}\right)$ are two important groups of compounds for oxygen storage, catalysis, and luminescence applications [36-38]. The compounds are traditionally
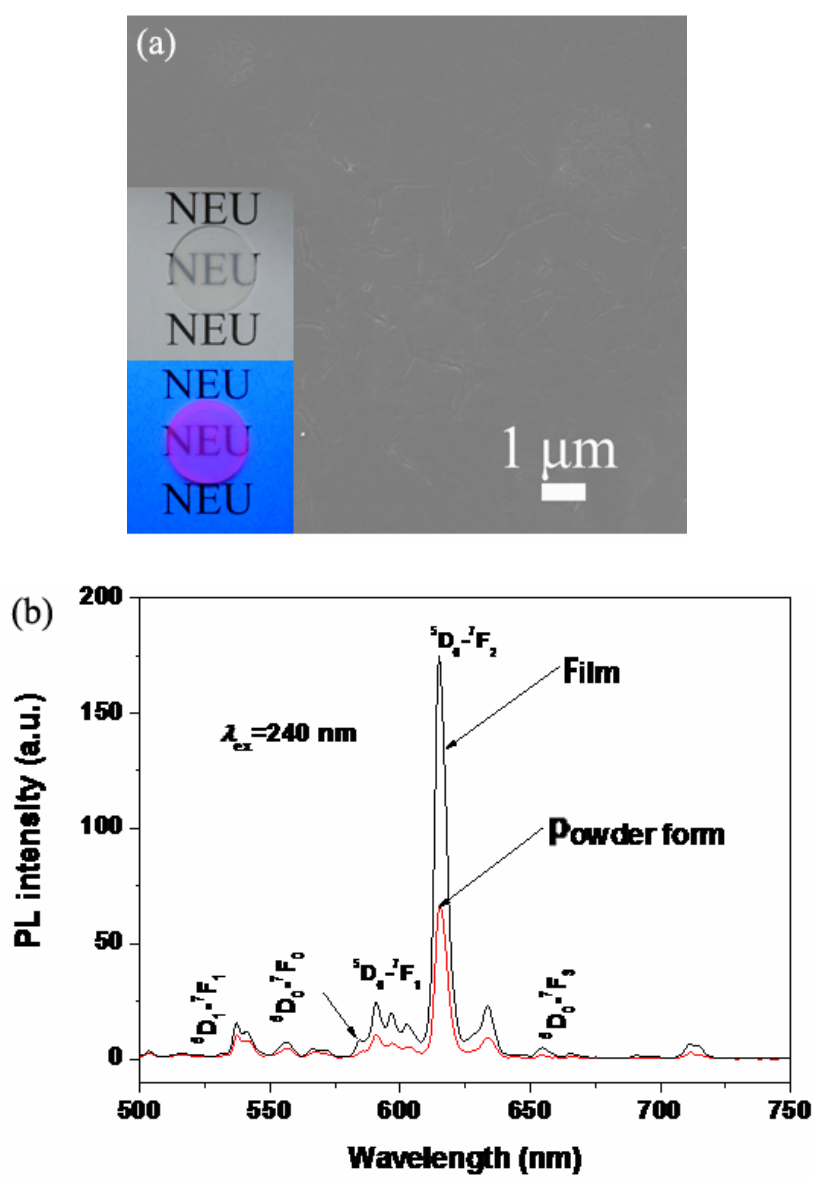

Fig. 7 FE-SEM image of the oriented $\left(\mathrm{Y}_{0.95} \mathrm{Eu}_{0.05}\right)_{2} \mathrm{O}_{3}$ film and a comparison of the PL spectra of the powder and film forms. Reproduced with permission from Ref. [25], (C) National Institute for Materials Science 2014.

synthesized with the involvements of environmentally harmful sulfur-containing reagents, such as elemental $\mathrm{S}$, $\mathrm{CS}_{2}, \mathrm{H}_{2} \mathrm{~S}$, and so on. Taking advantage of the fact that the sulfate-type 241-LRH has exactly the same S/Ln molar ratio of $\mathrm{Ln}_{2} \mathrm{O}_{2} \mathrm{SO}_{4}$ and $\mathrm{Ln}_{2} \mathrm{O}_{2} \mathrm{~S}$, we very recently achieved green synthesis (with water vapor as the only exhaust) of the latter two compounds using $\mathrm{Ln}_{2}(\mathrm{OH})_{4} \mathrm{SO}_{4} \cdot 2 \mathrm{H}_{2} \mathrm{O}$ as the precursor (Fig. 8) [9,24,36-38]. For example, $\left(\mathrm{La}_{0.95} \mathrm{Eu}_{0.05}\right)_{2} \mathrm{O}_{2} \mathrm{SO}_{4}$ red phosphor can be converted from $\left(\mathrm{La}_{0.95} \mathrm{Eu}_{0.05}\right)_{2}(\mathrm{OH})_{4} \mathrm{SO}_{4} \cdot 2 \mathrm{H}_{2} \mathrm{O}$ via annealing in air at a minimum temperature of $400{ }^{\circ} \mathrm{C}$ to achieve strong red emission at $620 \mathrm{~nm}$ (the ${ }^{5} \mathrm{D}_{0} \rightarrow{ }^{7} \mathrm{~F}_{2}$ transition of $\mathrm{Eu}^{3+}$ ) under $280 \mathrm{~nm}$ ultraviolet light excitation [36,38]. On the other hand, annealing $\left(\mathrm{La}_{0.95} \mathrm{Eu}_{0.05}\right)_{2}(\mathrm{OH})_{4} \mathrm{SO}_{4} \cdot 2 \mathrm{H}_{2} \mathrm{O}$ in flowing $\mathrm{H}_{2}$ at a minimum temperature of $\sim 700{ }^{\circ} \mathrm{C}$ directly produces $\left(\mathrm{La}_{0.95} \mathrm{Eu}_{0.05}\right)_{2} \mathrm{O}_{2} \mathrm{~S}$ red phosphor via the $\left(\mathrm{La}_{0.95} \mathrm{Eu}_{0.05}\right)_{2} \mathrm{O}_{2} \mathrm{SO}_{4}$ intermediate (Fig. 8) [37]. Photoluminescence excitation (PLE) studies found the two distinct charge transfer (CT) excitation bands of 


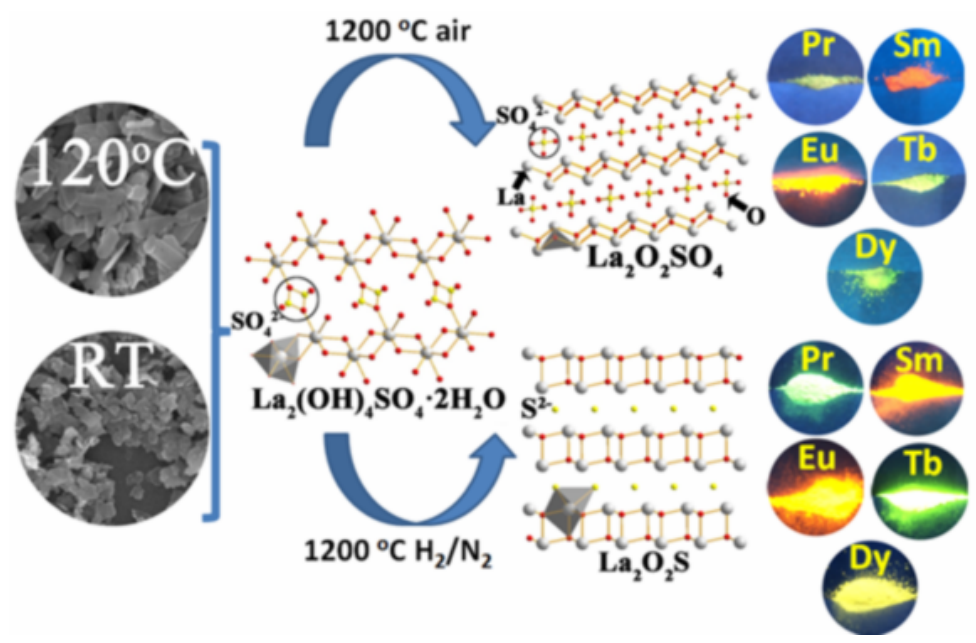

Fig. 8 ( $\mathrm{La}, \mathrm{RE})_{2} \mathrm{O}_{2} \mathrm{SO}_{4}$ oxysulfate and $(\mathrm{La}, \mathrm{RE})_{2} \mathrm{O}_{2} \mathrm{~S}$ oxysulfide phosphors $(\mathrm{RE}=\mathrm{Pr}, \mathrm{Sm}, \mathrm{Eu}, \mathrm{Tb}$, and Dy) derived with 241-L(La, RE)H as a green precursor for multi-color photoluminescence. Reproduced with permission from Ref. [9], (C) Elsevier B.V. 2016.

$\mathrm{O}^{2-} \rightarrow \mathrm{Eu}^{3+}$ at $\sim 270 \mathrm{~nm}$ and $\mathrm{S}^{2-} \rightarrow \mathrm{Eu}^{3+}$ at $\sim 340 \mathrm{~nm}$ for $\left(\mathrm{La}_{0.95} \mathrm{Eu}_{0.05}\right)_{2} \mathrm{O}_{2} \mathrm{~S}$, with the latter being stronger and both significantly stronger than the intrinsic intra- $4 \mathrm{f}^{6}$ transitions of $\mathrm{Eu}^{3+}$ [9]. Inserting the other important activators of $\mathrm{Pr}^{3+}, \mathrm{Sm}^{3+}, \mathrm{Tb}^{3+}$, and $\mathrm{Dy}^{3+}$ into the two hosts of $\mathrm{La}_{2} \mathrm{O}_{2} \mathrm{~S}$ and $\mathrm{La}_{2} \mathrm{O}_{2} \mathrm{SO}_{4}$ produced multi-color emissions including bright red, green, orange red, and yellow under ultraviolet excitation (Fig. 8), and the photoluminescent properties, in terms of excitation, emission, quantum yield, and color coordinates of emission, have been thoroughly investigated [9]. Detailed investigation of the $\mathrm{Tb}^{3+}$ emission revealed the lack of ${ }^{5} \mathrm{D}_{3}$ blue emission in $\mathrm{La}_{2} \mathrm{O}_{2} \mathrm{~S}$ and a gradual quenching of ${ }^{5} \mathrm{D}_{3}$ emission at a higher $\mathrm{Tb}^{3+}$ content in $\mathrm{La}_{2} \mathrm{O}_{2} \mathrm{SO}_{4}$ (hence decreasing $I_{488} / I_{545}$ ratio and changing color coordinates), which were suggested to be due to thermal activation of the ${ }^{5} \mathrm{D}_{3}$ electrons of $\mathrm{Tb}^{3+}$ into the conduction band of the host lattice and cross relaxation among the adjacent $\mathrm{Tb}^{3+}$ ions, respectively [24]. Extended successes have also been achieved in the green derivation of $\mathrm{Ln}_{2} \mathrm{O}_{2} \mathrm{~S}$ and $\mathrm{Ln}_{2} \mathrm{O}_{2} \mathrm{SO}_{4}$ for the other Ln elements of La-Dy [24]. The photoluminescence properties of $\mathrm{Eu}^{3+}$ and $\mathrm{Tb}^{3+}$ were thoroughly investigated and compared for the two hosts of $\mathrm{Gd}_{2} \mathrm{O}_{2} \mathrm{~S}$ and $\mathrm{Gd}_{2} \mathrm{O}_{2} \mathrm{SO}_{4}$, and cathodoluminescence investigation of $\left(\mathrm{Gd}_{0.99} \mathrm{~Tb}_{0.01}\right)_{2} \mathrm{O}_{2} \mathrm{~S}$ found that the phosphor is stable under electron beam irradiation and exhibited an increasingly higher emission brightness as the acceleration voltage (up to $7 \mathrm{kV}$ ) or beam current (up to $50 \mathrm{~mA}$ ) increased [24]. The synthetic approach developed for $\mathrm{Ln}_{2} \mathrm{O}_{2} \mathrm{SO}_{4}$ and $\mathrm{Ln}_{2} \mathrm{O}_{2} \mathrm{~S}$ phosphors, with water vapor as the only exhaust gas, is environmentally benign and holds great potential for practical applications [24].

\section{Summary and outlook}

The structural features, controlled crystallization, anion exchange, nanosheet exfoliation, and application in the fields of phosphors and oriented films were demonstrated in this review article for both the $\mathrm{Ln}_{2}(\mathrm{OH})_{5}\left(\mathrm{~A}^{x-}\right)_{1 / x} \cdot n \mathrm{H}_{2} \mathrm{O} \quad$ (251-LRHs) and $\mathrm{Ln}_{2}(\mathrm{OH})_{4}\left(\mathrm{~A}^{x-}\right)_{2 / x} \cdot n \mathrm{H}_{2} \mathrm{O}$ (241-LRHs) groups of layered rare-earth hydroxides. Despite all the successes achieved up to date, difficulties are frequently encountered in synthesizing the 251-LRHs $\left(\mathrm{A}=\mathrm{NO}_{3}^{-}\right.$or $\left.\mathrm{Cl}^{-}\right)$of the largest $\mathrm{La}^{3+}$ and smallest $\mathrm{Yb}^{3+}$ and $\mathrm{Lu}^{3+}$ ions and the $\mathrm{Ln}_{2}(\mathrm{OH})_{4} \mathrm{SO}_{4} \cdot 2 \mathrm{H}_{2} \mathrm{O}$ 241-LRHs of $\mathrm{Ln}=\mathrm{Ho}-\mathrm{Lu}$. It should also be noted that much more research efforts are needed to exfoliate large-sized LRH nanosheets in reasonable quantities in a more efficient way. With these issues being overcomed in the future, wider applications of the LRH compounds can be expected.

\section{Acknowledgements}

This work was supported in part by the National Natural Science Foundation of China (Grant Nos. 51672039 and 51702020), and the Fundamental Research Funds for the Central Universities (Grant No. N160204008).

\section{References}

[1] Ogawa M, Kuroda K. Photofunctions of intercalation 
compounds. Chem Rev 1995, 95: 399-438.

[2] Sasaki T, Watanabe M. Osmotic swelling to exfoliation. Exceptionally high degrees of hydration of a layered titanate. J Am Chem Soc 1998, 120: 4682-4689.

[3] Auerbach SM, Carrado KA, Dutta PK. Handbook of Layered Materials. New York: Marcel Dekker, Inc., 2004.

[4] Liu Z, Ma R, Osada M, et al. Synthesis, anion exchange, and delamination of $\mathrm{Co}-\mathrm{Al}$ layered double hydroxide: Assembly of the exfoliated nanosheet/polyanion composite films and magneto-optical studies. J Am Chem Soc 2006, 128: $4872-4880$.

[5] Gándara F, Perles J, Snejko N, et al. Layered rare-earth hydroxides: A class of pillary crystalline compounds for intercalation chemistry. Angew Chem Int Edit 2006, 45: 7998-8001.

[6] Geng F, Matsushita Y, Ma R, et al. General synthesis and structural evolution of a layered family $\mathrm{Ln}_{8}(\mathrm{OH})_{20} \mathrm{Cl}_{4} \cdot n \mathrm{H}_{2} \mathrm{O}(\mathrm{Ln}=\mathrm{Nd}, \mathrm{Sm}, \mathrm{Eu}, \mathrm{Gd}, \mathrm{Tb}, \mathrm{Dy}, \mathrm{Ho}, \mathrm{Er}$, Tm, and Y). J Am Chem Soc 2008, 130: 16344-16350.

[7] Zhu Q, Li J-G, Zhi C, et al. Layered rare-earth hydroxides (LRHs) of $\left(\mathrm{Y}_{1-x} \mathrm{Eu}_{x}\right)_{2}(\mathrm{OH})_{5} \mathrm{NO}_{3} \cdot n \mathrm{H}_{2} \mathrm{O}(x=0-1)$ : Structural variations by $\mathrm{Eu}^{3+}$ doping, phase conversion to oxides, and the correlation of photoluminescence behaviors. Chem Mater 2010, 22: 4204-4213.

[8] Liang J, Ma R, Geng F, et al. $\mathrm{Ln}_{2}(\mathrm{OH})_{4} \mathrm{SO}_{4} \cdot n \mathrm{H}_{2} \mathrm{O}$ (Ln: Pr to $\mathrm{Tb} ; n \approx 2$ ): A new family of layered rare-earth hydroxides rigidly pillared by sulfate ions. Chem Mater 2010, 22: 6001-6007.

[9] Wang X, Li J-G, Molokeev MS, et al. Layered hydroxyl sulfate: Controlled crystallization, structure analysis, and green derivation of multi-color luminescent $(\mathrm{La}, \mathrm{RE})_{2} \mathrm{O}_{2} \mathrm{SO}_{4}$ and $(\mathrm{La}, \mathrm{RE})_{2} \mathrm{O}_{2} \mathrm{~S}$ phosphors $(\mathrm{RE}=\mathrm{Pr}, \mathrm{Sm}$, $\mathrm{Eu}, \mathrm{Tb}$, and Dy). Chem Eng J 2016, 302: 577-586.

[10] Geng F, Xin H, Matsushita Y, et al. New layered rare-earth hydroxides with anion-exchange properties. Chem Eur $J$ 2008, 14: 9255-9260.

[11] Geng F, Matsushita Y, Ma R, et al. Synthesis and properties of well-crystallized layered rare-earth hydroxide nitrates from homogeneous precipitation. Inorg Chem 2009, 48: 6724-6730.

[12] McIntyre LJ, Jackson LK, Fogg AM. $\mathrm{Ln}_{2}(\mathrm{OH})_{5} \mathrm{NO}_{3} \cdot x \mathrm{H}_{2} \mathrm{O}$ $(\mathrm{Ln}=\mathrm{Y}, \mathrm{Gd}-\mathrm{Lu})$ : A novel family of anion exchange intercalation hosts. Chem Mater 2008, 20: 335-340.

[13] Poudret L, Prior TJ, McIntyre LJ, et al. Synthesis and crystal structures of new lanthanide hydroxyhalide anion exchange materials, $\mathrm{Ln}_{2}(\mathrm{OH})_{5} X \cdot 1.5 \mathrm{H}_{2} \mathrm{O}(X=\mathrm{Cl}, \mathrm{Br} ; \mathrm{Ln}=\mathrm{Y}$, Dy, Er, Yb). Chem Mater 2008, 20: 7447-7453.

[14] McIntyre LJ, Prior TJ, Fogg AM. Observation and isolation of layered and framework ytterbium hydroxide phases using in situ energy-dispersive X-ray diffraction. Chem Mater 2010, 22: 2635-2645.

[15] Wang X, Li J-G, Zhu Q, et al. Direct crystallization of sulfate-type layered hydroxide, derivation of $(\mathrm{Gd}, \mathrm{Tb})_{2} \mathrm{O}_{3}$ green phosphor, and photoluminescence. J Am Ceram Soc 2015, 98: 3236-3242.

[16] Lee K-H, Byeon S-H. Extended members of the layered rare-earth hydroxide family, $\mathrm{RE}_{2}(\mathrm{OH})_{5} \mathrm{NO}_{3} \cdot n \mathrm{H}_{2} \mathrm{O}(\mathrm{RE}=$ $\mathrm{Sm}, \mathrm{Eu}$, and $\mathrm{Gd}$ ): Synthesis and anion-exchange behavior.
Eur J Inorg Chem 2009, 7: 929-936.

[17] Lee K-H, Byeon S-H. Synthesis and aqueous colloidal solutions of $\mathrm{RE}_{2}(\mathrm{OH})_{5} \mathrm{NO}_{3} \cdot n \mathrm{H}_{2} \mathrm{O}(\mathrm{RE}=\mathrm{Nd}$ and La). Eur J Inorg Chem 2009, 31: 4727-4732.

[18] Zhu Q, Li J-G, Ma R, et al. Well-defined crystallites autoclaved from the nitrate/ $\mathrm{NH}_{4} \mathrm{OH}$ reaction system as the precursor for $(\mathrm{Y}, \mathrm{Eu})_{2} \mathrm{O}_{3}$ red phosphor: Crystallization mechanism, phase and morphology control, and luminescent property. J Solid State Chem 2012, 192: 229-237.

[19] Zhu Q, Li J-G, Zhi C, et al. Nanometer-thin layered hydroxide platelets of $\left(\mathrm{Y}_{0.95} \mathrm{Eu}_{0.05}\right)_{2}(\mathrm{OH})_{5} \mathrm{NO}_{3} \cdot x \mathrm{H}_{2} \mathrm{O}$ : Exfoliation-free synthesis, self-assembly, and the derivation of dense oriented oxide films of high transparency and greatly enhanced luminescence. J Mater Chem 2011, 21: 6903-6908.

[20] Wu X, Li J-G, Zhu Q, et al. One-step freezing temperature crystallization of layered rare-earth hydroxide $\left(\mathrm{Ln}_{2}(\mathrm{OH})_{5} \mathrm{NO}_{3} \cdot n \mathrm{H}_{2} \mathrm{O}\right)$ nanosheets for a wide spectrum of $\mathrm{Ln}(\mathrm{Ln}=\mathrm{Pr}-\mathrm{Er}$, and $\mathrm{Y})$, anion exchange with fluorine and sulfate, and microscopic coordination probed via photoluminescence. J Mater Chem C 2015, 3: 3428-3437.

[21] Zhu Q, Li J-G, Li X, et al. $\left[\left(\mathrm{Y}_{1-x} \mathrm{Gd}_{x}\right)_{0.95} \mathrm{Eu}_{0.05}\right]_{2}$ $(\mathrm{OH})_{5} \mathrm{NO}_{3} \cdot n \mathrm{H}_{2} \mathrm{O} \quad(0 \leqslant x \leqslant 0.50)$ layered rare-earth hydroxides: Exfoliation of unilamellar and single-crystalline nanosheets, assembly of highly oriented and transparent oxide films, and greatly enhanced red photoluminescence by $\mathrm{Gd}^{3+}$ doping. RSC $A d v 2015,5$ : 64588-64595.

[22] Wu X, Li J-G, Li J, et al. Layered rare-earth hydroxide (LRH) and oxide nanoplates of the $\mathrm{Y} / \mathrm{Tb} / \mathrm{Eu}$ system: Phase controlled processing, structure characterization, and color-tunable photoluminescence via selective excitation and efficient energy transfer. Sci Technol Adv Mater 2013, 14: 015006.

[23] Wu X, Li J-G, Ping DH, et al. Structure characterization and photoluminescence properties of $\left(\mathrm{Y}_{0.95-x} \mathrm{Gd}_{x} \mathrm{Eu}_{0.05}\right)_{2} \mathrm{O}_{3}$ red phosphors converted from layered rare-earth hydroxide (LRH) nanoflake precursors. J Alloys Compd 2013, 559: 188-195.

[24] Wang X, Li J-G, Molokeev MS, et al. Hydrothermal crystallization of a $\mathrm{Ln}_{2}(\mathrm{OH})_{4} \mathrm{SO}_{4} \cdot n \mathrm{H}_{2} \mathrm{O}$ layered compound for a wide range of $\mathrm{Ln}(\mathrm{Ln}=\mathrm{La}-\mathrm{Dy})$, thermolysis, and facile transformation into oxysulfate and oxysulfide phosphors. RSC Adv 2017, 7: 13331-13339.

[25] Zhu Q, Li J-G, Li D, et al. Tens of micron-sized unilamellar nanosheets of $\mathrm{Y} / \mathrm{Eu}$ layered rare-earth hydroxide: Efficient exfoliation via fast anion exchange and their self-assembly into oriented oxide filmwith enhanced photoluminescence. Sci Technol Adv Mater 2014, 15: 014203.

[26] $\mathrm{Hu} \mathrm{L}$, Ma R, Ozawa TC, et al. Exfoliation of layered europium hydroxide into unilamellar nanosheets. Chem Asian J 2010, 5: 248-251.

[27] Zhu Q, Xu Z, Li J-G, et al. Hydrothermal-assisted exfoliation of $\mathrm{Y} / \mathrm{Tb} / \mathrm{Eu}$ ternary layered rare-earth hydroxides into tens of micron-sized unilamellar nanosheets for highly oriented and color-tunable nano-phosphor films. Nanoscale Res Lett 2015, 10: 132. 
[28] Wu X, Li J-G, Zhu Q, et al. The effects of $\mathrm{Gd}^{3+}$ substitution on the crystal structure, site symmetry, and photoluminescence of $\mathrm{Y} / \mathrm{Eu}$ layered rare-earth hydroxide (LRH) nanoplate. Dalton Trans 2012, 41: 1854-1861.

[29] Zhu Q, Zhang X, Li J-G, et al. Oriented and yellow-emitting nano-phosphor films of high transparency assembled from exfoliated nanosheets of layered rare-earth hydroxide (LRH). J Nanosci Nanotechnol 2017, 17: 2471-2477.

[30] Liu L, Wang Q, Gao C, et al. Dramatically enhanced luminescence of layered terbium hydroxides as induced by the synergistic effect of $\mathrm{Gd}^{3+}$ and organic sensitizers. $J$ Phys Chem C 2014, 118: 14511-14520.

[31] Liu L, Yu M, Zhang J, et al. Facile fabrication of color-tunable and white light emitting nano-composite films based on layered rare-earth hydroxides. $J$ Mater Chem C 2015, 3: 2326-2333.

[32] Shen T, Zhang Y, Liu W, et al. Novel multi-color photoluminescence emission phosphors developed by layered gadolinium hydroxide via in situ intercalation with positively charged rare-earth complexes. J Mater Chem C 2015, 3: 1807-1816.

[33] Su F, Gu Q, Ma S, et al. Delaminated layered rare-earth hydroxide composites with ortho-coumaric acid: Color-tunable luminescence and blue emission due to energy transfer. J Mater Chem C 2015, 3: 7147-7152.

[34] Gu Q, Su F, Ma S, et al. Intercalation of coumaric acids into layered rare-earth hydroxides: Controllable structure and photoluminescence properties. J Mater Chem C 2015, 3: 4741-4750.

[35] Xie L, Liu C, Ma L, et al. A unique delaminated $\mathrm{MoS}_{4} /$ OS-LEuH composite exhibiting turn-on luminescence sensing for detection of water in formamide. Dalton Trans 2017, 46: 3110-3114.

[36] Wang X, Li J-G, Zhu Q, et al. Photoluminescence of $(\mathrm{La}, \mathrm{Eu})_{2} \mathrm{O}_{2} \mathrm{SO}_{4}$ red-emitting phosphors derived from layered hydroxide. J Mater Res 2016, 31: 2268-2276.

[37] Wang X, Li J-G, Zhu Q, et al. Facile and green synthesis of $\left(\mathrm{La}_{0.95} \mathrm{Eu}_{0.05}\right)_{2} \mathrm{O}_{2} \mathrm{~S}$ red phosphors with sulfate-ion pillared layered hydroxides as a new type of precursor: Controlled hydrothermal processing, phase evolution, and photoluminescence. Sci Technol Adv Mater 2014, 15: 014204.

[38] Wang X, Li J-G, Zhu Q, et al. Synthesis, characterization, and photoluminescence properties of $\left(\mathrm{La}_{0.95} \mathrm{Eu}_{0.05}\right)_{2} \mathrm{O}_{2} \mathrm{SO}_{4}$ red phosphors with layered hydroxyl sulfate as precursor. J Alloys Compd 2014, 603: 28-34.

Open Access The articles published in this journal are distributed under the terms of the Creative Commons Attribution 4.0 International License (http://creativecommons. org/licenses/by/4.0/), which permits unrestricted use, distribution, and reproduction in any medium, provided you give appropriate credit to the original author(s) and the source, provide a link to the Creative Commons license, and indicate if changes were made. 